\section{International Scientific Journal Theoretical \& Applied Science}

\author{
p-ISSN: 2308-4944 (print) e-ISSN: 2409-0085 (online) \\ Year: $2015 \quad$ Issue: 09 Volume: 29 \\ Published: $30.09 .2015 \quad$ http://T-Science.org
}

SECTION 8. Architecture and construction.
Manuchar Tamazovich Shishinashvili

Doctor of engineering Sciences, Professor,

National Defence Academy of Georgia,

Georgia

$\underline{\text { m.shishinashvili@gmail.com }}$

Giorgi Gizoevich Tsimakuridze

student, IV year,

Georgian Technical University,

Georgia

tsimaka@gmail.com

\title{
USE OF SEMI FIXED COMPOSITE SURFACES AT GEORGIAN
}

Abstract: In the work is discussed the recommendation of implantation and using of semi fixed composite surface in the itinerary infrastructure of Georgia. Are discussed positive and negative sides of the surfaces of such type, the technologies and peculiarities of their arrangement. In the work are compared physic-mechanical peculiarities of semi fixed composite surface and compared with the practical asphalt concrete arranged surface.

Key words: semi fixed composite surface, asphalto concrete, concrete surface.

Language: Russian

Citation: Shishinashvili MT, Tsimakuridze GG (2015) USE OF SEMI FIXED COMPOSITE SURFACES AT GEORGIAN. ISJ Theoretical \& Applied Science 09 (29): 33-35.

Soi: http://s-o-i.org/1.1/TAS-09-29-8 Doi: crossef http://dx.doi.org/10.15863/TAS.2015.09.29.8

\section{УСТРОЙСТВО ПОЛУЖЕСТКОГО КОМПОЗИЦИОННОГО ПОКРЫТИЯ В ГРУЗИИ}

Аннотация: В статье был проведен обзор дорожной инфраструктуры Грузии, развитие и использование полужестких композиционных покрытии. Также был проведен обзор плюсов и минусов такого типа покрытии, технология укладки и физико-механические особенности, в статье показаны физико-механические свойства традиционных асфальтобетонов и полужёстких композиционньх покрытий.

Ключевые слова: полужёсткие композиционные покрытия, асфальтобетон, цементобетонная покрытие.

Развитие автомобильной дорожной сети в Грузии вошло в активную фазу. Проводится реабилитация существующих автомобильных дорог, а также укладываются новые автомагистрали.

Мы считаем целесообразным во время реабилитации дорог низкой категории использовать полужесткий композитный настил.

Использование такого типа покрытия на дорогах низшей категории позволит снизить затраты. Это очень важно для экономического развития страны. Укладывание дорог таким покрытием требует низкие энергетические затраты, что будет направлено на снижение вредных воздействии на окружающую среду. Полужесткое композитное покрытие эффективно в горной местности, что является идеальным вариантом в нашем случае.

Структура асфальтобетона формируется на всех этапах технологического процесса. Этапы для каждой разновидности асфальтобетонной смеси имеют свои особенности, что отражается в конкретном Технологическом регламенте.
Регламент содержит требования к исходным материалам и продукции, результаты оценки их качества на соответствие требуемым показателям, подобранную рецептуру смеси, перечень необходимой техники и оборудования, описание технологического процесса и его параметры, экономические показатели и др.

Технология устройства полужесткого композиционного покрытия из черного щебня и цемент песчаного раствора предопределяется конструктивной особенностью жесткой прослойки и покрытия в целом.

Для таких покрытий используют в основном традиционные дорожные машины и агрегаты. Однако в зависимости от конкретных условий и конструктивных особенностей покрытий не исключена необходимость конструирования специальных узлов механизмов для приспособления существующих дорожных машин и агрегатов к технологическим процессам пропитки слоя черного щебня цемент песчаным раствором или введения структурных армирующих элементов в тело нежесткого 
покрытия. Все зависит от творческого подхода; строителя к решению вопроса.

При пропитке слоя черного щебня сверху (прямая пропитка) вдавливание цемент песчаного раствора в пустоты (в поры) слоя черного щебня осуществляют пневмокатками или виброкатками. Для этих целей можно использовать также площадочные вибраторы. При выборе катков следует учесть, что цемент песчаный раствор легко прилипает к барабанам гладко вальцевых катков, затрудняя процесс вдавливания раствора в слой черного щебня.

Для обеспечения нормального процесса пропитки в раствор следует вводить супер пластификатор. Контрольное определение глубины пропитки на месте позволяет непосредственно на дороге корректировать норму расхода и консистенцию (подвижность) раствора в зависимости от размера образовавшихся при уплотнении слоя черного щебня пустот (пор), вида пластификатора в средства вдавливания раствора в слой черного щебня.

Число проходов катка составляет примерно 4-5 по одному следу.

Процесс вдавливания раствора в слой черного щебня считается законченным, когда черный щебень выступает под поверхностью слоя цемент песчаного раствора на $3-4$ мм. Выступающие грани щебня обеспечивают определенную шероховатость жесткого слоя при использовании его в качестве верхнего или, контактируя с горячей асфальтобетонной смесью, увеличивают сцепление с верхним слоем при использовании жесткой прослойки в качестве нижнего слоя.

Обеспечение нормативного количества разливаемого цемент песчаного раствора является необходимым условием, так как при избытке может образоваться сплошной (непрерывный) слой из цемент песчаного раствора над слоем черного щебня, что является дефектом и отступлением от принципа устройства полужесткого покрытия.

При пропитке раствором слоя черного щебня снизу (обратной пропитке) технология несколько упрощается, так как давление на цемент песчаный раствор передается непосредственно через слой черного щебни, подлежащего пропитке.

Для укатки слоя черного щебня можно использовать все виды катков, применяемых для укатки дорожных покрытий. Следует отметить, что при обратной пропитке качество жесткой прослойки несколько снижается, и такой способ преимущественно применим при использовании жесткой прослойки в качестве нижнего слоя, лежащего при этом на .плотном основании.
В летнее время для обеспечения нормального тепло-влажностного режима твердения цемента, слой горячего черного щебня поливают водой до (при прямой пропитке) и после (при обратной пропитке) пропитки раствором в количестве 5-10 л. на кв.м. покрытия с использованием традиционных поливочных машин.

Полный технологический цикл устройства полужесткого композиционного покрытия при прямой пропитке состоит из следующих операций:

Приготовление черного щебня на центральных базах и доставка его в горячем состоянии $\left(130-150^{\circ} \mathrm{C}\right)$ на дорогу автосамосвалами;

Устройство слоя из черного щебня по существующей технологии.

Специфика настоящей технологии заключается только в том, что количество прохода катка по одному следу ограничивается из условии образования крупнопористого слоя черного щебня, легко пропитываемого цемент песчаный раствором;

Приготовление цемент песчаного раствора (при необходимости с добавками пластификатора и полимера) на месте в передвижных растворомешалках или на центральных базах и доставка на дорогу авто бетоновозами, автосамосвалами или специально оборудованными транспортными средствами;

Выгрузка цемент песчаного раствора непосредственно на слой черного щебня и разравнивание его самоходным укладчиком дорожно-строительных материалов (смесей), автогрейдером. Количество раствора составляет $3,5-4,5 л$ на кв.м. и на 1 см. глубины пропитки покрытия;

Вдавливание цемент песчаного раствора до начала схватывания цемента в крупнопористый слой черного щебня пневмокатками или виброкатками.

Разлив битумной эмульсии в количестве 0,4 л. на 1 кв.м. покрытия автогудронатором по готовому слою' черного щебня, пропитанного цемент песчаным раствором, при использовании его в качестве верхнего слоя и укладка верхнего слоя из мелкозернистой асфальтобетонной смеси асфальт укладчиком без перерыва, при использовании его в качестве нижнего слоя, с последующим уплотнением ее катками;

Если жесткая прослойка служит верхним слоем основания, сразу же после пропитки слоя черного щебня цемент песчаным раствором укладывают нижний слой асфальтобетона. При этом верхний слой асфальтобетона может быть уложен с перерывом в несколько дней, но лучше не задерживать больше одних суток. 
Спустя 24 часа выдержки готовое покрытие можно передавать в эксплуатацию.

При устройстве покрытия способом обратной пропитки технологическая последовательность несколько меняется: вначале разравнивают цемент песчаный раствор по готовому основанию, а затем укладывают слой черного щебня. Его распределяют по свежеуложенному слою раствора обычными распределителями щебня или асфальт укладчиком. Укатку производят пневмокаткамн, виброкатками или, при их отсутствии, обыкновенными жестковальцовыми катками, до полного втапливания щебня в слой цемент песчаного раствора и до появления на поверхности раствора. Сразу же по окончании пропитки устраивают верхний слой асфальтобетонного покрытия.

При двухсторонней, при обратной и потом прямой пропитке более толстых слоев черного щебня обе операции можно выполнять одновременно или с определенным перерывом между ними.

\section{References:}

1. Burduladze A, Shishinashvili M, Magradze M, Bakuradze T (2014) PERSPECTIVES OF USE OF COLD RECYCLING IN THE ROAD SECTOR OF GEORGIA. IHJVT< B TRANSACTIONS TRUDY, 113.

2. Shishinashvili M (2014) ASPHALT SURFACE RECYCLING ACCORDING TO THE HOT METHOD. inteleqtuali, 148.

3. Burduladze AR, Shishinashvili MT, Magradze MD (2014) IMPROVEMENT OF THE QUALITY OF THE ASPHALT MIX. ISJ Theoretical \& Applied Science, 02 (10): 44-47. doi:

http://dx.doi.org/10.15863/TAS.2014.02.10.7

4. CHEN, Bai-ling, Shu-hong WANG, and Yumei KANG. "The Design of Reliability of
Asphalt Pavement Structure." Western China Communications Science \& Technology 5 (2008): 017.

5. Burduladze AR, Bezhanishvili MG, Shishinashvili MT (2014) EXISTING IN GEORGIA LOCAL ROAD CONSTRUCTION MATERIALS AND THEIR OPTIMAL USE IN THE CONSTRUCTION OF PAVEMENT. ISJ Theoretical \& Applied Science 12 (20): 6164.doi:

http://dx.doi.org/10.15863/TAS.2014.12.20.14

6. Sivilevičius, Henrikas, and Valentinas Podviezko. "Conditional optimization mathematical model of the asphalt concrete mixture grading." Journal of Civil Engineering and Management 8.2 (2002). 